\title{
Factors involved in the development of the metabolic syndrome. We are what we eat and what we are eating
}

\author{
Hiroaki Masuzaki
}

\author{
From 7th APPES Biennial Scientific Meeting \\ Nusa Dua, Bali. 14-17 November 2012
}

A variety of metabolic and molecular changes in brain and adipose tissue play a critical role in the pathophysiology of life style-related metabolic diseases [1-3]. Even in obese subjects with insulin resistance in skeletal muscle and liver, insulin action on adipose tissue remains intact or rather exaggerated, resulting in considerable difficulties in weight reduction. Excess in circulating insulin thus causes body fat gain as well as ectopic lipid overload in liver, skeletal and cardiac muscle, pancreas and vasculature. The adipocyte hormone, leptin controls feeding behavior, augments fatty acid $\beta$-oxidation in the skeletal muscle and enhances whole body insulin sensitivity, thereby serving as a promising therapeutic candidate for the treatment of obesity-diabetes syndrome. However, the clinical application of leptin has been hampered by the notion that leptin does not fully exert its metabolic effects in subjects with fat diet-induced obesity [4-6]. It is important to note that the future risk of cardiometabolic diseases exists for infants with low birth weight/intrauterine growth retardation (IUGR). IUGR causes a premature leptin surge in the neonatal period in mice, and conceivably, through a number of epigenetic mechanisms, it may induce hypothalamic leptin resistance in adulthood. Mechanisms of non-genomic, intergenerational transmission of metabolic diseases from parents to children have also been unveiled in an expeditious fashion. The endoplasmic reticulum (ER) is an intracellular organelle involved in protein folding and apoptosis. The accumulation of misfolded proteins in the ER, termed as ER stress, is involved in the molecular pathophysiology of type 2 diabetes and metabolic syndrome. Our recent research in mice demonstrated that high fat diet-induced ER stress

Division of Endocrinology, Diabetes and Metabolism, Hematology, and Rheumatology, Second Department of Medicine, Graduate School of Medicine, University of the Ryukyus, Okinawa, Japan in the hypothalamus plays a pivotal role in the preference for fatty foods and resultant increase in body weight. We provided the first evidence that brown rice and its major component, $\gamma$-oryzanol, ameliorate glucose dyshomeostasis in mice fed high-fat diet (HFD), accompanied by reduction of hypothalamic endoplasmic reticulum (ER) stress [7]. In my talk, I try to review the update of mechanisms of metabolic syndrome, with a particular focus on the molecular food sciences.

Published: 3 October 2013

\section{References}

1. Masuzaki $\mathrm{H}$, et al: Nonadipose tissue production of leptin: Leptin as a novel placenta-derived hormone in humans. Nature Med 1997, 3:1029-1033, (senior author).

2. Masuzaki $\mathrm{H}$, et al: A transgenic model of visceral obesity and the metabolic syndrome. Science 2001, 294:2166-2170, (senior author).

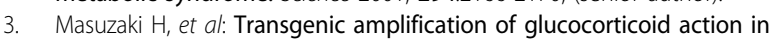
adipose tissue causes high blood pressure in mice. J Clin Invest 2003, 112:83-90, (senior author).

4. Masuzaki $\mathrm{H}$, et al: Glucose metabolism and insulin sensitivity in transgenic mice overexpressing leptin with lethal Yellow agouti mutation.-Usefulness of leptin for the treatment of obesity-associated diabetes-. Diabetes 1999, 48:1615-1622, (senior author).

5. Masuzaki $H$, et al: Increased glucose metabolism and insulin sensitivity in transgenic skinny mice overexpressing leptin. Diabetes 1999, 48:1822-1829, (senior author).

6. Masuzaki $\mathrm{H}$, et al: Central melanocortin signaling restores skeletal muscle AMP-activated protein kinase phosphoylation in mice fed a high fat diet. Cell Metabolism 2007, 5:395-402, (corresponding author).

7. Masuzaki $\mathrm{H}$, et al: Brown rice and its components, $\mathrm{Y}$-orizanol, attenuate the preference for high fat diet by decreasing hypothalamic endoplasmic reticulum stress in mice. Diabetes 2012.

doi:10.1186/1687-9856-2013-S1-O3

Cite this article as: Masuzaki: Factors involved in the development of the metabolic syndrome. We are what we eat and what we are eating. International Journal of Pediatric Endocrinology 2013 2013(Suppl 1):O3. (c) 2013 Masuzaki; licensee BioMed Central Ltd. This is an Open Access article distributed under the terms of the Creative Commons Attribution License (http://creativecommons.org/licenses/by/2.0), which permits unrestricted use, distribution, and reproduction in any medium, provided the original work is properly cited. 